\title{
The Problems of Designing and Creating \\ a Pilot Plant Producting Biogas \\ from Animal Waste APK Siberia
}

\author{
Marina P. Baranova*, \\ Valentin M. Ekaterinchev ${ }^{a}$ and Nikita L. Abashev ${ }^{b}$ \\ ${ }^{a}$ Krasnoyarsk State Agrarian University \\ 90 Mira, Krasnoyarsk, 660049, Russia \\ ${ }^{b}$ Siberian Federal University \\ 79 Svobodny, Krasnoyarsk, 660041, Russia
}

Received 02.09.2016, received in revised form 24.11.2016, accepted 02.01.2017

The paper establishes the basic aspects that must be taken into consideration in designing the biogas setting to process the animal breeding wastes and processing industry of Siberian agroindustrial complex in particular Krasnoyarsk region. The basic schemes of technical support were determined for biogas production technological process and organic fertilizers as a byproduct. The experimental site for pilot plant placing was chosen, the locality binding and the pilot plant's laboratories designing was made.

Keywords: biogas setting, animal breeding wastes, organic fertilizers.

Citation: Baranova M.P., Ekaterinchev V.M., Abashev N.L. The problems of designing and creating a pilot plant producting biogas from animal waste APK Siberia, J. Sib. Fed. Univ. Eng. technol., 2017, 10(1), 106-112. DOI: 10.17516/1999-494X-201710-1-106-112

(C) Siberian Federal University. All rights reserved

* Corresponding author E-mail address: bash22zel@mail.ru 


\title{
Проблемы проектирования
}

\section{и создания опытно-промышленной установки \\ получения биогаза}

\section{из отходов животноводства АПК Сибири}

\author{
М.П. Баранова ${ }^{\text {a }}$ В.М. Екатеринчев ${ }^{\text {a }}$ Н.Л. Абашев ${ }^{\sigma}$ \\ ${ }^{a}$ Красноярский государственный аграрный университет \\ Россия, 660049, Красноярск, пр. Мира, 90 \\ ${ }^{6}$ Сибирский федеральный университет \\ Россия, 660041, Красноярск, пр. Свободный, 79
}

B статье установлены основные аспекты, которые необходимо учитывать при проектировании биогазовой установки для переработки отходов животноводства и перерабатывающей промышленности АПК Сибири, в частности Красноярского края. Определены основные схемы технического обеспечения технологического прочесса получения биогаза и, как побочный продукт, органических удобрений. Выбрана площадка для размещения опытно-промышленной установки, произведена привязка к местности, проведены работы по проектированию помещения для опытно-промышленной установки.

Ключевые слова: биогазовая установка, отходы животноводства, органические удобрения.

\section{Введение}

В настоящее время существует необходимость такого подхода к организации производства в сельском хозяйстве, когда оно должно работать по автономному циклу или по замкнутой системе. Это необходимо и возможно потому, что практически все отходы имеют органическое происхождение и состоят из углеводородов, которые, в свою очередь, являются исходным материалом для получения энергии и ряда веществ.

В Красноярском крае достаточно остро стоит проблема утилизации отходов животноводства, особенно отходов крупных свиноводческих комплексов.

Целью работы была оценка возможности проектирования и создания опытнопромышленной биогазовой установки для отработки технологии переработки отходов животноводческих хозяйств для климатических условий Восточной Сибири.

Само по себе использование биогазовой станции, особенно на территории Красноярского края, абсолютная инновация. Именно поэтому часто встречается необоснованное мнение о том, что эта технология сложна и затратна. Все это приводит к необходимости адаптирования технологии получения биогаза из отходов для условий Сибири, что может решить задачи:

1) энергоснабжения либо снижения затрат на энергоснабжение для производства тепловой и электрической энергии для нужд хозяйства;

2) получения практически бесплатного органического удобрения, готового для внесения в почву. Причем это удобрение безопасно как с химической, так и с биологической точек зрения.

В некоторых случаях переработка отходов с получением удобрения является целевой.

$$
-107-
$$


Эксплуатация установки позволит определить технологические и технические особенности, возможности упрощения или удешевления процесса. Необходимость создания опытнопромышленной установки в крае обусловлена еще и тем, что производители представляют лишь общую информацию о технологическом процессе. Собственные ноу-хау производители держат в строгом секрете, что объясняется жесткими условиями конкуренции на рынке биогазовой энергетики. К тому же край, обладая высокими возможностями производить необходимое оборудование на месте, может снизить затраты на капитальные затраты по созданию и тиражированию установок любой производительности.

Экономический эффект от внедрения технологии биоконверсии комплексный. Применение органических удобрений из остатка увеличивает урожайность сельскохозяйственных культур. По некоторым экспериментальным данным, внесение в почву органосодержащего остатка после анаэробной ферментации обеспечивает дополнительный прирост урожайности на 15-25 \% на каждую тонну сухого остатка. Кроме того, биогаз можно конвертировать в тепловую энергию, электроэнергию (когенерация) и использовать непосредственно как топливо для заправки транспорта [1].

Экологические аспекты:

- минимизация загрязнения воздушного бассейна около агропромышленного комплекca;

- отсутствие загрязнения почвы и грунтовых вод органическими соединениями;

- снижение использования минеральных удобрений;

- сокращение санитарно-защитной зоны агропромышленных предприятий (например, рекомендуемая С33 свинофермы на 100000 голов - 12 км, после строительства биогазовой станции - 300 м);

- получение «органических» продуктов;

- обеззараживание органических отходов животноводства и птицеферм [2].

\section{Проблемы проектирования опытно-промышленной установки}

Биогазовая станция - это комплекс инженерных сооружений, состоящий из устройств подготовки сырья, производства биогаза и удобрений, очистки и хранения биогаза, производства электроэнергии и тепла, автоматизированной системы управления биогазовой станцией и других установок.

Технология имеет все признаки индивидуальности - в каждом отдельном случае возможно и порой необходимо выполнять индивидуальный проект.

Процесс проектирования и создания опытно-промышленной установки вызывает сложности уже на самом первом этапе. Это обусловлено целым рядом вопросов, возникающих при адаптации технологии к климатическим условиям, а именно:

- выбор технологии сбраживания. В зависимости от требований и желания потребителя на установке может осуществляться мезофильный либо термофильный режим, который позволяет получить удобрения с практически стерильными характеристиками;

- применение либо неприменение вносимых штаммов, что возможно при мезофильном режиме. При использовании термофильного режима периодическое внесение штаммов необходимо; 
- степень однородности подаваемого сырья. Исходным сырьем может быть и навоз, и птичий помет, и иловые остатки очистных сооружений, и измельченные отходы органической массы (животных). Соответственно, чем мельче частицы, тем эффективнее идет процесс ферментации и процесс выделения метана ускоряется и увеличивается;

- способ и периоды перемешивания зависят от производительности установки, состава исходного сырья, технических возможностей обеспечения технологического процесca;

- временные периоды внесения исходного материала и отведения продуктов влияют на количество и скорость выделения биогаза и к тому же определяются качеством и количеством штаммов - смеси энзимов, пробиотиков и микроэлементов;

- влажность исходного материала;

- способ обогрева метантенка. Проще всего использовать подогретую воду. В литературе отсутствует информация о возможности применения в качестве теплоносителя для системы поддержания температуры в реакторе нагретого воздуха или других газов;

- распределение тепловых полей внутри реактора и связанные с этим процессы эффективной работы микроорганизмов;

- выбор объема метантенка опытно-промышленной установки для того, чтобы полученные на нем данные можно было масштабировать как в сторону уменьшения объема (для небольших фермерских хозяйств), так и в сторону увеличения (для промышленных агрокомплексов);

- выбор материала, из которого сделан реактор, поскольку это влияет на производительность по газу, на обогрев, что может снизить потребляемое тепло на собственные нужды и не должно влиять на качество среды обитания микроорганизмов или возникновения вторичных реакций;

- выбор перемешивающих устройств (мешалки погружные с определенной скоростью импеллера, рамочные мешалки или барботаж);

- выбор дробильного, насосного оборудования, запорно-регулирующей и предохранительной арматуры;

- определение схемы подачи исходного сырья и отведения полученного продукта.

\section{Предлагаемые схемы биогазовых установок для ООО «Емельяновское»}

В ходе работы определена площадка для размещения опытно-промышленной установки, произведена привязка к местности, осуществлено проектирование помещения для опытнопромышленной установки. В зависимости от технологических особенностей процесса переработки отходов животноводства возможно разное техническое обеспечение и, соответственно, цена. От этого зависит и определение схемы подачи исходного сырья и отведения полученного продукта.

После проведенного анализа для размещения опытно-промышленной установки по получению биогаза и органических удобрений выбрано ООО «Емельяновское», которое расположено в 26 км от г. Красноярска. Были рассмотрены две технологические схемы получения биогаза 
1

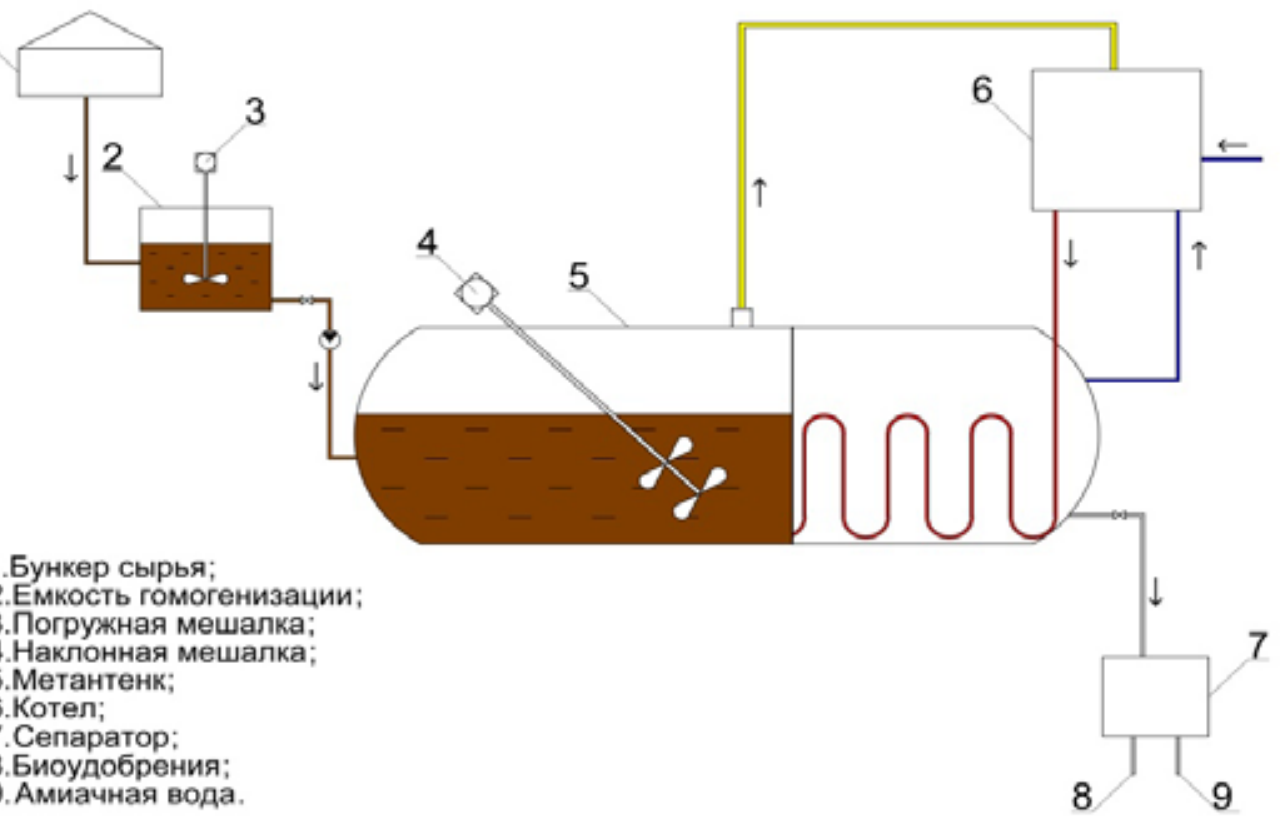

a)

- Субстрат; - Подогретая вода;

- Охлажденная вода: $\square$ - Биогаз

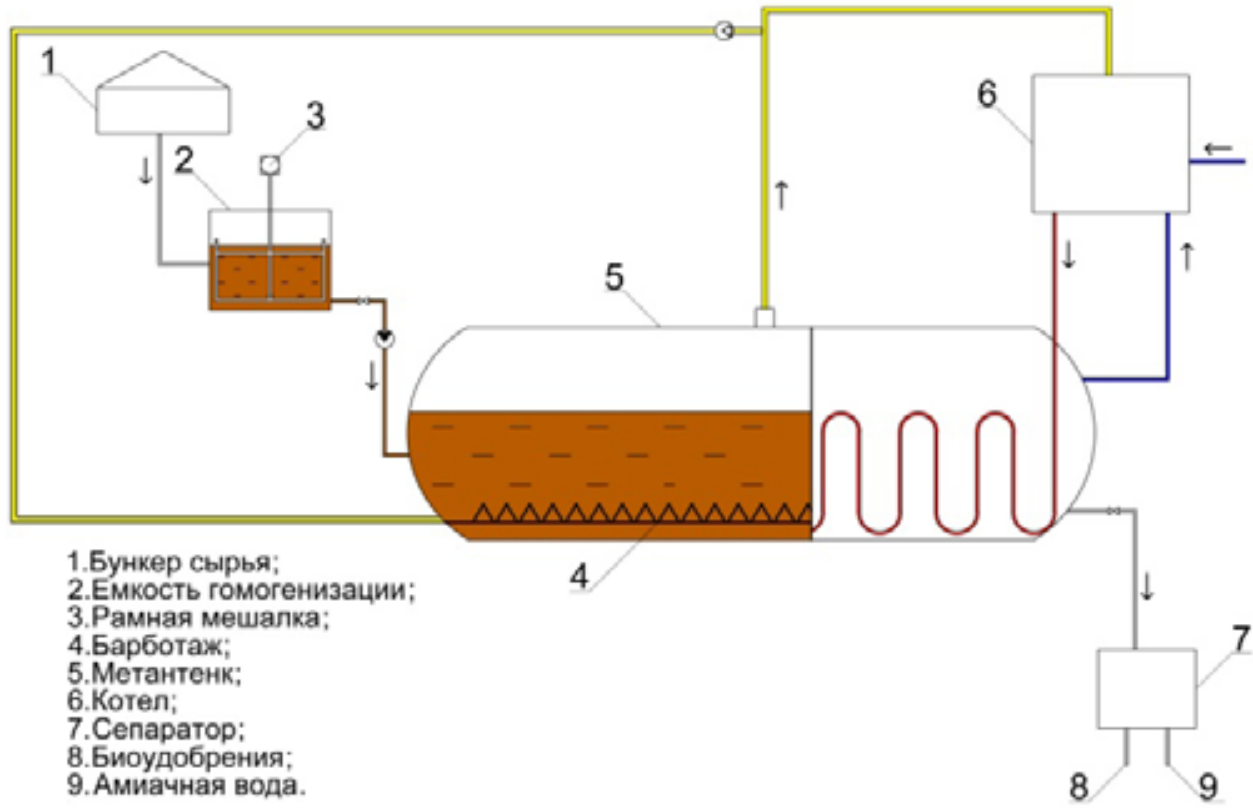

б)

Рис. Технологические схемы опытно-промышленной биогазовой установки: a - с применением механических мешалок; б - с применением барботажа 
(рис. $a, \sigma)$. При оценке производительности установки, экономичности и с учетом качества исходного сырья (в основном навоз КРС) определена компоновка оборудования, соответствующая схеме б. Объем реактора $20 \mathrm{~m}^{3}$. Соответственно, количество получаемого биогаза $\approx 24 \mathrm{M}^{3}$, обогрев собственным газом (32-44 \% расход газа на собственные нужды в холодное время). Компремирование газа не предусмотрено. Полученный газ сжигается для покрытия тепловых нагрузок на собственные нужды (отопление, вентиляция, ГВС).

Определены условия эффективной работы биогазовой станции, которые заключаются в следующем:

- постоянная температура в биореакторе от 35 до $72{ }^{\circ} \mathrm{C}$ в зависимости от выбранного режима;

- работа установки осуществляется в автоматическом режиме;

- количество технического персонала 3-5 человек;

- автоматическая линия загрузки сырья;

- использование когенерационной установки, позволяющей достигать КПД до 95 \%.

Следует отметить, что в ходе создания и эксплуатации биогазовой установки будут внесены некоторые изменения в технологическую схему и схему размещения оборудования.

Установка не может работать на открытом воздухе, поскольку климатические условия Красноярского края этого не позволяют. Для размещения оборудования запланировано строительство помещения. В качестве ограждающих конструкций определены сэндвич-панели. Для замены или установки добавочного оборудования как минимум одна стена должна быть разборной. Именно невозможность внесения оборудования в существующее помещение явилась одной из причин отказа от ряда возможных площадок.

\section{Заключение}

В результате проведенной работы установлены основные аспекты, которые необходимо учитывать при проектировании биогазовой установки для переработки отходов животноводства и перерабатывающей промышленности АПК Сибири, в частности Красноярского края. Определены основные схемы технического обеспечения технологического процесса получения биогаза и, как побочный продукт, органических удобрений. Выбрана площадка для размещения опытно-промышленной установки, произведена привязка к местности, проведены работы по проектированию помещения для опытно-промышленной установки.

\section{Список литературы}

[1] Росбиогаз. Предпосылки к развитию биогазовых технологий в России [Электронный pecypc] - Режим доступа: http://www.rosbiogas.ru/predposilki-k-razvitiyu-biogazovix-texnologij-vrossii.html - Заглавие с экрана. [Rusbiogas. Background to the development of biogas technologies in Russia [Electronic resourse] - Access: http://www.rosbiogas.ru/predposilki-k-razvitiyu-biogazovixtexnologij-v-rossii.html

[2] Росбиогаз. Руководство по биогазовым технологиям [Электронный ресурс] - Режим доступа: http://www.rosbiogas.ru/literatura/rukovodstvo-po-biogazovim-texnologiyam/ - Заглавие с экрана. [Rusbiogas. Biogas Guide [Electronic resource] - Access: http://www.rosbiogas.ru/literatura/ rukovodstvo-po-biogazovim-texnologiyam/_ 
[3] Баадер В. Биогаз: теория и практика; пер. с нем. М.И. Серебряного; М.: Мир, 1992. 148 c. [Baader V. Biogas: theory and practice. Transl. from Ger. By M.I. Serebraniy; Moscow, Mir, 1992, 148 p. (in Russian)] 